\title{
Fatores que influenciam o não acesso da população aos serviços de alta complexidade do SUS
}

\author{
Factors that influence the population's failure to access high complexity SUS services \\ Factores que influyen en la falta de acceso de la población a servicios SUS de alta complejidad
}

Recebido: 14/10/2021 | Revisado: 20/10/2021 | Aceito: 25/10/2021 | Publicado: 28/10/2021

\author{
Andreza Souza Lopes Valadão \\ ORCID: https://orcid.org/0000-0002-6042-330X \\ Faculdade Integrada Carajás, Brasil \\ E-mail: andrezavictoria15@gmail.com \\ Iasmyn Almeida Pereira Guedes \\ ORCID: https://orcid.org/0000-0001-6520-8732 \\ Faculdade Integrada Carajás, Brasil \\ E-mail: iasmynguedes47@gmail.com \\ Patrícia Maria Lima Silva de Sousa \\ ORCID: https://orcid.org/0000-0002-2985-5163 \\ Faculdade Integrada Carajás, Brasil \\ E-mail: patriciasousa50anos@gmail.com
}

\begin{abstract}
Resumo
$\mathrm{O}$ acesso à saúde é um direito social humano básico. O estudo visa discorrer sobre os fatores que influenciam o não acesso da população aos serviços de alta complexidade do SUS, e compreender como funciona a atenção à saúde. Trata-se de uma revisão bibliográfica integrativa com abordagem qualitativa, realizada por meio de pesquisa em revistas eletrônicas, livros e a legislação pertinente à temática. É impossível separar os vetores da dignidade humana e do direito à saúde, que é um instrumento de efetividade e exigibilidade dos direitos para o exercício da cidadania constitucionalizada afirmando princípios da solidariedade e da igualdade de direito à vida, como um importante aliado da coletividade na busca pela concretização dos direitos fundamentais. Os dados evidenciaram a necessidade de uma legislação que desperte o poder público para voltar o olhar e regulamentar em lei a definição desse problema social que é essencial para romper com o desrespeito de direito à saúde. Evidenciou que as instituições de controle de políticas de saúde possuem um papel importante no zelo pelas ações e serviços de saúde, através de acompanhamento dos instrumentos de planejamento, gestão e do controle do SUS e da execução das políticas públicas de saúde. O prejuízo da população do não acesso aos serviços de alta complexidade do SUS é uma realidade em muitas unidades de saúde do país, e que referem-se a ineficiente gestão de recursos humanos sendo imprescindível o envolvimento de todos profissionais que assistem à população adstrita em ações de qualificação especializada e capacitações frequentes.
\end{abstract}

Palavras-chave: Alta complexidade do SUS; Compreensão do funcionamento da atenção à saúde no SUS.

\begin{abstract}
Access to health is a basic human social right. The study aims to discuss the factors that influence the population's lack of access to highly complex SUS services, and to understand how health care works. This is an integrative literature review with a qualitative approach, carried out through research in electronic journals, books and legislation relevant to the subject. It is impossible to separate the vectors of human dignity and the right to health, which is an instrument of effectiveness and enforceability of rights for the exercise of constitutionalized citizenship, affirming principles of solidarity and equal rights to life, as an important ally of the community in the search for the realization of fundamental rights. The data evidenced the need for legislation that awakens the public authorities to turn their gaze and regulate in law the definition of this social problem, which is essential to break with the disrespect of the right to health. It showed that health policy control institutions play an important role in the zeal for health actions and services, through monitoring the planning, management and control instruments of the SUS and the execution of public health policies. The loss of the population from not having access to highly complex SUS services is a reality in many health units in the country, which refer to the inefficient management of human resources, and the involvement of all professionals who assist the population involved in actions is essential, specialized qualification and frequent training.
\end{abstract}

Keywords: High complexity of the SUS; Understanding how health care works in the SUS.

\section{Resumen}

El acceso a la salud es un derecho social humano básico. El estudio tiene como objetivo discutir los factores que influyen en la falta de acceso de la población a servicios de alta complejidad del SUS y comprender cómo funciona la 
atención de la salud. Se trata de una revisión bibliográfica integradora con enfoque cualitativo, realizada a través de la investigación en revistas electrónicas, libros y legislación relevante en la materia. Es imposible separar los vectores de la dignidad humana y el derecho a la salud, que es un instrumento de efectividad y exigibilidad de los derechos para el ejercicio de la ciudadanía constitucionalizada, afirmando principios de solidaridad e igualdad de derechos a la vida, como importante aliado de la comunidad. En la búsqueda de la realización de los derechos fundamentales. Los datos evidenciaron la necesidad de una legislación que despierte a los poderes públicos para volver la mirada y regular en la ley la definición de este problema social, que es fundamental para romper con la falta de respeto al derecho a la salud. Demostró que las instituciones de control de las políticas de salud juegan un papel importante en el afán por las acciones y servicios de salud, a través del seguimiento de los instrumentos de planificación, gestión y control del SUS y la ejecución de las políticas públicas de salud. La pérdida de la población por no tener acceso a servicios del SUS de alta complejidad es una realidad en muchas unidades de salud del país, que hacen referencia a la gestión ineficiente de los recursos humanos, y es fundamental la participación de todos los profesionales que atienden a la población involucrada en las acciones, cualificación especializada y formación frecuente.

Palabras clave: Alta complejidad del SUS; Comprender cómo funciona la atención de la salud en el SUS.

\section{Introdução}

Historicamente a saúde no Brasil iniciou-se com os cuidados de entidades filantrópicas e religiosas com atenção através da caridade. As Santas Casas de Misericórdia se responsabilizavam em atender as pessoas que necessitavam de atenção à saúde e o Estado intervenções de caráter emergenciais.

Em 1923 por meio da Lei Eloy Chaves através do Decreto n. 4.682 de 24 de janeiro de 1923 consolidou a base da previdência do Brasil iniciando as Caixas de Aposentadorias e Pensão - CAP, organizadas entre empresa e empregado, em regime de capitalização. No ano de 1930 o Presidente Getúlio Vargas substituiu as CAPs pelos Institutos de Aposentadorias e Pensões - IAP, centralizados no governo federal, em que a associação deixou de ser por empresa e passou a ser por categorias profissionais. (Fernandes \& Sousa, 2019).

A partir de 1964 o governo intensificou suas ações em saúde com a criação de uma comissão para o sistema previdenciário que unificasse os IAPs em um sistema único, em 1966 foi criado o Instituto Nacional de Previdência Social INPS. Configurou-se uma comunidade profissional, associada ao poder público, que passou a ser voz ativa dos grupos que tinham interesses vinculados às atividades nas áreas da saúde e do saneamento.

Desde então, diversos atores sociais como os intelectuais, lideranças políticas, profissionais da saúde, movimentos estudantis e sindicais, iniciaram um debate em torno de um sistema de saúde para todos. Foram décadas de luta por um sistema mais igualitário e universal, com necessidade de uma estrutura organizativa, participativa e transparente, por meio da elaboração de políticas públicas, formação dos profissionais da saúde, gerenciamento, fiscalização, investimento de recursos e participação da comunidade, para garantir a existência e eficiência de um Sistema Único de Saúde - SUS. (Fernandes e Sousa, 2019).

O Sistema Único de Saúde foi criado pela Constituição de 1988, (Brasil, 1988) “Constituição Cidadã” considerada a constituição mais completa que já teve no Brasil, principalmente no que se referem aos direitos de cidadania. O SUS é uma conquista histórica do povo brasileiro, expressão de uma política de Estado que se fundamenta em uma concepção ampliada de saúde e em uma perspectiva universalista do direito à saúde, traduzida em princípios (valores), diretrizes (políticas e organizativas) e dispositivos jurídicos (leis e normas) que orientam e definem o curso das ações governamentais em todas as esferas de governo (Gil et al, 2016; Mendes, 2019).

O atual sistema de saúde brasileiro, universal, vive um momento de intensos avanços, na garantia da assistência e tratamento para saúde individual e coletiva, abrangendo a baixa e alta complexidade, mas também de muitos desafios como o repasse financeiro e dificuldades na gestão de recursos. (Baptista, 2011; Fernandes \& Sousa, 2019). 
A saúde da população e a prestação de serviços de saúde estão expostos a influências externas e internas que podem comprometer tanto as condições de saúde da população como facilitar ou dificultar a obtenção da qualidade, produtividade ou custos de prover serviços.

Especificamente, no que diz respeito a programas e serviços de saúde, as variáveis externas são epidemiológicas, geográficas, demográficas, socioeconômicas, culturais e de mercado, devendo ser conhecidas e trabalhadas, visando efetividade e eficiência. Quanto às internas, se devem a vários fatores, como organizacionais, de recursos pessoal e material, financeiros, informacionais, fluxos operacionais internos, necessitando de informação para possibilitar agregação e tomada de decisão. (Nogueira Bittar et al, 2018; Pery, 2015).

Nesse contexto grande parte das não conformidades detectadas nos relatórios de auditória do SUS não se referem ao suprimento financeiro, mas ao processo de trabalho, de tomada de decisões do gestor ou das gerencias, maioria delas atributos de gestão que pode ser solucionada pela via administrativa.

Sendo assim, o objetivo do estudo é discorrer sobre os fatores que influenciam o não acesso da população aos serviços de alta complexidade do SUS, bem como compreender como funciona a atenção à saúde. Considera-se que o despertar do poder público para voltar o olhar e regulamentar em lei a definição desse problema social é essencial para romper com o desrespeito de direito fundamental à saúde.

\section{Metodologia}

\subsection{Tipo de estudo}

O estudo trata de uma revisão bibliográfica integrativa com abordagem qualitativa que fundamenta o estado atual das informações do tema investigado, Ramos (2018), consiste numa metodologia adequada à área da saúde, sistematiza a síntese de estudos sobre a temática especifica e direciona a pratica de estudos científicos, acurada através de artigos publicados para identificar os fatores que estão relacionados as dificuldades enfrentadas pela população em conseguir acesso aos serviços ofertados pela alta complexidade do SUS, crise econômica e má administração dos gestores, bem como identificar lacunas para futuros estudos.

\subsection{Coleta de dados}

No estudo buscou-se artigos publicados nas bases de dados Biblioteca Virtual em Saúde (BVS), Literatura LatinoAmericana e do Caribe em Ciências da Saúde (LILACS) e Scientific Eletronic Library Online (SciELO). Foi realizado também consulta a sites da Organização Mundial da Saúde (OMS), Portarias e Leis do Ministério da Saúde, livros e revistas especializadas no tema. Utilizou-se como descritores para a consulta às bases de dados: alta complexidade do SUS, compreensão do funcionamento da atenção à saúde no SUS. Sendo analisados cerca de 10 artigos, 1 Lei, 1 publicações da OMS e uma Pesquisa Nacional publicada pela DATASUS na língua portuguesa e apresentando um recorte temporal de 2015 a 2021.

\subsection{Critérios de inclusão e exclusão dos artigos}

Os artigos inclusos foram publicados nos últimos 6 anos em português e inglês que abordam os fatores que influenciam o não acesso da população aos serviços de alta complexidade do SUS fazendo uma relação com a pratica do funcionamento da atenção à saúde no SUS e estão disponibilizados eletronicamente na íntegra e excluídos os artigos que foram publicados fora do limite temporal 2015 a 2021 e que não estejam disponíveis eletronicamente na íntegra. 
Tabela 1: Critérios de inclusão e exclusão.

\begin{tabular}{|c|c|}
\hline INCLUSÃO & EXCLUSÃO \\
\hline Artigos publicados de 2015 a 2021 & Artigos anteriores a 2000 \\
\hline Estudos em Língua Portuguesa e inglesa & Estudos em Língua espanhola \\
\hline $\begin{array}{l}\text { Que abordam fatores que influenciam o não acesso da } \\
\text { população aos serviços de alta complexidade do SUS }\end{array}$ & $\begin{array}{l}\text { Que abordam outras situações que não seja a } \\
\text { referente à alta complexidade }\end{array}$ \\
\hline $\begin{array}{l}\text { Que discorrem sobre a prática a pratica do } \\
\text { funcionamento da atenção à saúde no SUS }\end{array}$ & $\begin{array}{l}\text { Que discorrem sobre a prática fora da } \\
\text { obstetrícia/parto }\end{array}$ \\
\hline Textos completos & Textos incompletos. \\
\hline
\end{tabular}

Fonte: Autores (2021).

Após fazer a pré-leitura dos artigos filtrados e selecionados com base nos critérios de inclusão e seleção, restaram 10 (dez) artigos que subsidiam a presente pesquisa. Os dados coletados foram tratados utilizando a Técnica de Análise de Conteúdo de Bardin (2017) que analisa a temática sob três momentos: a pré-análise, a exploração do material e o tratamento dos resultados que consiste na interpretação dos estudos.

\section{Resultados e Discussão}

\subsection{O direito social à saúde fundamental a dignidade humana}

O conceito amplo de saúde apresentado pela Organização Mundial de Saúde (OMS) atribui um conjunto de valores que objetiva possibilitar aos indivíduos um completo bem estar físico, mental e social. Estes na visão de Nahsan; Martins; Daltro; Bianchi (2020) com base em Sarlet, (2015) sustenta que:

Se observados, possibilitam a prevenção de potenciais enfermidades e, acaso estas venham a se manifestar, possibilitam o mais amplo acesso aos meios de cura. Agrega, assim, um conjunto de elementos multidisciplinares, encetando em si o mais completo aspecto de proteção ao ser humano (Nahsan et al, 2020, p.89).

Para esses autores, consequentemente, a saúde atribui ser um direito fundamental social, requer políticas públicas de maneira preventiva, na área da educação, da qualidade de vida, boas condições hospitalares, laboratórios de qualidade, equipe médica especializada e benefícios alcançados pelo próprio Estado ou com redes privadas de saúde. Caso esse direito fundamental à saúde não seja respeitado, por inexistência de recursos suficientes ao atendimento ou pela ausência de políticas públicas adequadas, acarreta a possibilidade de discussão no âmbito do poder judiciário, (Ramos et tal, 2016) visando resguardar tal direito.

Martini (2017, p. 27) enfatiza que em tempos atuais, a saúde é um direito fundamental e também um importante investimento social. Na medida em que o estado visa melhorar as condições de saúde de todos os cidadãos, é preciso que invistam recursos em políticas públicas de saúde capazes de garantir programas efetivos para a sua promoção, porém é necessário constituir um princípio fundamental de justiça social, porque, exige também uma grande produtividade complexa da sociedade e do Estado, cuja intensificação solicita uma ação integração de esforços para coordenar as intervenções econômicas sociais e sanitárias.

Pensar hoje em "direito à saúde e dignidade da pessoa humana" remete à ideia de implementação e busca da consolidação dos direitos humanos, pois afinal, ser cidadão é ter consciência de que se é "sujeito de direitos," civis, políticos e sociais, efetiva o direito à vida e consequentemente à saúde. Desta maneira contribui para o efetivo exercício da cidadania, uma sociedade de cidadãos é uma sociedade de relações democráticas baseada na igualdade entre as pessoas e, sobretudo no respeito pela dignidade humana. O cidadão tem de ser cônscio das suas responsabilidades enquanto parte integrante de um 
grande e complexo organismo que é a coletividade, a nação e o Estado, onde todos são responsáveis pela concretização de direitos. Assim se chega ao bem comum. (Martini, 2017, p.38).

Nahsan et al, (2020) no que diz respeito ao direito à saúde, destaca Bastos e Martins (1988) que faz menção ao artigo 196 da Constituição Federal de 1988 (Brasil,1988):

Artigo 196 da CF: Por fim, tais políticas deveriam objetivar o acesso universal e igualitário às ações e serviços do governo, para que a saúde da população seja promovida, protegida e recuperada. Tanto a promoção quanto a proteção nessa área dependem de que sejam reunidos os instrumentos de atuação de Estado, degradados nos últimos tempos, assim como a elaboração de estratégia para a recuperação dos doentes. Quem lê o artigo 196 tem a impressão de que o País está acima das demais nações no que diz respeito à saúde, tanto nas ações profiláticas quanto naquelas de recuperação dos doentes. Quem vive a realidade da grande maioria da população brasileira menos favorecida percebe quão distante está o sonho do constituinte da prática dos detentores do poder (Nahsan; Martins; Daltro; Bianchi, 2020, p.91).

Portanto, um direito social humano básico e inacessível, a saúde requer um posicionamento de nível nacional, intervindo na sociedade por meio de políticas públicas e da prestação de serviços públicos, para garantir a dignidade de todas as pessoas sem distinção ou preconceitos, ter condições de saúde adequada, incluindo os aspectos físicos, psicológicos e sociais da saúde, e tratando a saúde como um bem individual, coletivo e em construção. Se por um lado o direito subjetivo à saúde é irrevogável e com garantia de aplicação imediata, por outro lado, nas interpretações contemporâneas dos direitos sociais, é fato que os serviços públicos de saúde do Brasil estão em crise e requer intervenção do Estado com o objetivo de reduzir os problemas de saúde, as desigualdades sociais e realizar os mencionados direitos humanos básicos. (Nahsan et al, 2020, p.91).

Para Martini (2017, p.39) é impossível de separar os vetores da dignidade humana e do direito à saúde, solidificando instrumento de efetividade e exigibilidade dos direitos fundamentais em direção à positivação do exercício da cidadania representada pela concretização de direitos e pela perspectiva de afirmar princípios da solidariedade e da igualdade, já que o direito à saúde é direito à vida, o bem máximo da humanidade. Logo, os pressupostos do princípio da dignidade da pessoa humana, enquanto fator legitimador do direito à saúde, afirmam-se como um importante aliado da coletividade na busca pela concretização dos tão idealizados direitos fundamentais.

\subsection{O princípio da saúde pública do SUS}

Os princípios que norteiam o funcionamento do Sistema Único de Saúde (SUS), insculpidos na Lei Federal n ${ }^{\circ} 8.080$, de 19 de setembro de 1990 (Lei Orgânica da Saúde), notadamente a universalidade de acesso, a integralidade de assistência e a preservação da autonomia (incisos I, II e III, respectivamente, do artigo $7^{\circ}$ ), estipula as condições e funções dos serviços de saúde para que um sistema único de saúde possa promover a saúde de acordo com a Constituição Federal, cujo texto legal prioriza as ações preventivas e comunicar seus direitos e riscos à saúde à população. (Nahsan et al, 2020, p.91); (Machado, Baptista \& Lima, 2018).

Os órgãos de controle de Políticas Públicas de Saúde, através da experiência da promotora de justiça do Ministério Público do Estado do Tocantins, doutora Roseli Pery (2015) leva a compreender como funciona a atenção à saúde no SUS que enfatiza que desde a criação do SUS (1992) tem passado por vários processos de organização, 2006 especificamente após a publicação das Políticas Nacional da Atenção Básica, o Ministério Público brasileiro tem avançado na sua forma de atuar dentro da sua missão institucional, sobretudo de defesa do direito social à saúde (Cayres, et al, 2020) e no campo das políticas públicas deixando de "olhar para a tutela do direito individual como a instituição cujo no início priorizou a sua atuação". Em tempos atuais conta-se com o primeiro projeto nacional de atuação do Ministério Publico voltado para a execução de políticas públicas da Atenção Básica. 
O referido projeto foi lançado no ano de 2014 cujo objetivo principal é a melhoria da qualidade da atenção básica, assim como o Programa Nacional de Melhoria do Acesso e da Qualidade da Atenção Básica (PMAQ) O PMAQ-AB tem como objetivo incentivar os gestores e as equipes a melhorar a qualidade dos serviços de saúde oferecidos aos cidadãos do território, especificamente aprimorar a atuação do Ministério Público na execução dessa política usando como ferramenta não somente o PMAQ, mas também outros instrumentos de controle do sistema único de saúde, assim como monitoramento controle de avaliação, supervisões, auditorias.

Conforme Pery (2015), a experiência foi bastante exitosa, pois no lançamento do Projeto Nacional em São Luiz do Maranhão, contou com adesão de grande parte dos ministérios públicos e aos poucos foram aderindo. O projeto na fase de execução já teve um diagnóstico da importância dele por que permitiu, sobretudo ver as não conformidades encontradas neste processo de monitoramento dentro do PMAQ, com base nessas informações das não conformidades que o Ministério Publico desenha sua atuação zelando pela execução de políticas públicas de saúde, seja na obrigação de fazer ou em eventuais ações de responsabilização.

Dentro dessas vertentes, no campo da qualificação do Ministério Público para atuarem de acordo com esse plano lançado foi realizado parceria entre a Fiocruz e Copeds, contando ainda com apoio da UNB e USP e cada Ministério Público também por meio de seus Centro de Estudos e Aperfeiçoamento Funcional no desenvolvimento de suas metodologias para promotores e procuradores que atuam nesta área.

Com relação a não conformidades detectadas pelo PMAQ Pery (2015) enfatiza que as principais referem-se a gestão de recursos humanos, existe em grande parte de Unidades de Saúde o não cumprimento de carga horaria, principalmente por parte de alguns médicos, na medida em que o médico não se encontra na Unidade Básica de Saúde desenvolvendo as políticas da atenção básica, a população adstrita fica desassistida com isso aquele problema de saúde que poderia ser enfrentado no primeiro nível de atenção seja, Atenção Básica ou Primaria, acaba se perdendo aquela oportunidade e em muitos casos, a situação de saúde passa a se agravar requerendo uma assistência no segundo nível de Atenção ou até mesmo no Terceiro, já em Unidades Hospitalares, tornando-se um prejuízo para a população do ponto de vista individual, coletivo e para o sistema uma vez que onera o sistema inclusive do ponto de vista de erário.

\subsubsection{Conceito de alta complexidade do SUS}

Com base no Departamento de Informática do SUS, a Atenção Primária corresponde a porta de entrada do sistema de saúde por possuir uma tecnologia de baixa densidade a atenção básica inclui vários procedimentos mais simples e com custos baixos capazes de atender a maior parte dos problemas comuns de saúde da comunidade, apesar de sua organização, desenvolvimento e aplicação podem demandar de outros níveis de saúde.

A alta e média complexidade do SUS constituem um conjunto de serviços e procedimentos (Thomaz, 2018, p.15) que garantem a resolutividade e integralidade da assistência à saúde, dando continuidade ao primeiro nível de atenção à saúde, a Atenção Básica. A média complexidade diz respeito a ações e serviços que visam atender problemas e agravos da saúde da população, na qual exista a demanda de profissionais especializados e recursos de apoio para o diagnóstico e tratamento. Enquanto que a alta complexidade refere-se ao conjunto de procedimentos que envolvem alta tecnologia e custo, objetivando propiciar a população acesso a serviços qualificados. 
Tabela 2. Dentre os atendimentos da Alta Complexidade, destacam-se:

\begin{tabular}{l|l} 
1. Assistência ao paciente oncológico; & 7. Procedimentos de Neurocirurgia; \\
\hline 2. Cirurgia cardiovascular: cirurgia vascular/pediátrica; & 8. Assistência em otologia; \\
\hline 3. Procedimentos da cardiologia intervencionista; & 9. Cirurgia de implante coclear; \\
\hline 4. Procedimentos endovascular extra cardíacos; & $\begin{array}{l}\text { 10. Cirurgia das vias áreas superiores e da região } \\
\text { cervical; }\end{array}$ \\
\hline 5. Laboratório de e eletrofisiologia; & $\begin{array}{l}\text { 11. Cirurgia da calota craniana da face e do sistema } \\
\text { estomatognática; }\end{array}$ \\
\hline 6. Assistência em traumato-ortopedia; & $\begin{array}{l}\text { 12. Procedimentos em fissuras lábio-palatais; }\end{array}$
\end{tabular}

Fonte: Adaptado pelas autoras (2021).

O SUS dispõe de programas para que seja possível o acesso e a organização da média e alta complexidade: a exemplo do TFD (Tratamento Fora do Domicilio) que objetiva garantir o acesso de pacientes de um município a servos assistenciais em outro município, ou ainda, em caso especial, de um Estado para outro Estado. O TFD pode envolver a garantia de transporte para tratamento e hospedagem, quando indicado. O tratamento é concedido exclusivamente a pacientes atendidos na rede pública e referenciada. Nos casos de indicação médica será autorizado o pagamento de despesas para acompanhante.

Outra normatização refere-se à Rede de Atenção Psicossocial composta pelo CAPS/Centros de Atenção Psicossocial, o SRT/Serviço Residencial Terapêutico e pelos Ambulatórios de Saúde Mental que são serviços especializados no atendimento as pessoas com transtornos mentais e comportamentais ou também devido ao uso de substancias psicoativas. É ofertado atendimento psicológico, psiquiátrico, consulta de enfermagem, serviço social e oficinas terapêuticas, objetivando a recuperação, bem como a reabilitação e reinserção social.

Existe ainda Centros de Especialidades Odontológicas (CEO) unidades destinadas ao atendimento odontológico especializado e atendimento a Pessoas com Deficiência. (CONASS, 2015).

Outro programa que possibilita o acesso a alta complexidade pelo SUS é o Centro de marcação de consultas especializadas e exames cujo serviço é responsável pelo agendamento de consultas especializadas e pela autorização e/ou agendamento de exames. Existe ainda o Ambulatório de especialidades (AME) que são unidades de alta resolutividade que oferecem consultas com especialistas, exames, sendo possível até a realização de pequenas cirurgias.

Embora o SUS disponibilize esses serviços de média e alta complexidade, a maioria não é suficiente para atender a demanda, ocorrendo ações judiciais em busca de obter o serviço.

Em fevereiro de 2020 o Cadastro Nacional de Estabelecimentos de Saúde (CNES), apontava no Brasil a existência de 46 mil unidades de UTI. Metades deles está disponível para o SUS, de brasileiros, e a outra metade é reservada à saúde privada ou suplementar (planos de saúde), que atende a aproximadamente $22 \%$ da população. (Queiroz e Sarmento, 2021).

Atualmente muitas decisões estabelecem para esses serviços sejam efetivados. Em casos de acesso a leitos de UTI/Unidades de Terapia Intensiva são mais frequentes “demandas judiciais” (Chagas, Provin, Amaral, 2016) visando garantir acessos a esses leitos.

\subsection{Compreensão do funcionamento da atenção à saúde no SUS}

\subsubsection{Olhar dos órgãos de controle de políticas públicas da saúde}

Em conformidade com os Órgãos de controle das políticas de saúde pública, composto pelo Ministério Público, Comissão Permanente em Defesa da Saúde (Copeds), Direitos Humanos, Secretaria de Gestão Estratégica e Participativa, do 
Ministério da Saúde, Fiocruz, através da promotora de justiça de Saúde Pública do Estado Tocantins, Roseli Pery (2015) faz um apanhado geral do funcionamento da atenção à saúde no SUS.

O acesso aos níveis médio e alta complexidade cuja realidade mostra problema nos três níveis de atenção à saúde: Primaria, Secundária e Terciária e os motivos são inúmeros. No segundo nível de atenção, especificamente o maior gargalo é a falta de médicos especialistas capazes de dar a cobertura que o pais necessita.

De acordo com Pery lá em 1988 quando na Constituição Federal no seu artigo 200 diz "que é competência do SUS ordenar a formação de recursos humanos na área da saúde", o Brasil levou muito tempo para ordenar essa formação de Recursos Humanos, contudo foi a partir do Programa "mais médicos" voltado no momento emergencial da atenção básica que o país se empoderou do que deveria ter feito em 1988 e passou a regular a formação medica no Brasil tanto com relação a formação especifica, quantidades de universidades, quanto em definir especialidade, apesar de avanço tardio, mas concreto.

Então na medida em que o pais não tem mão-de-obra suficiente para garantir um direito fundamental para todos de maneira universal e integral não tem como funcionar um sistema de saúde nesse sentido, por que se não fosse um direito fundamental não haveria de ser que o pais teria as dificuldades que tem hoje e os enfrentamentos que ele precisa fazer. Elencase a partir de agora em um olhar em médio e longo prazo será possível o Brasil conseguir organizar essa rede de atenção à saúde, pois na realidade o SUS para que consiga garantir esses direitos tomando por base as diretrizes e princípios dos sistemas, é imprescindível que a rede seja plenamente organizada por meio de regiões de saúde e observando a hierarquização.

No ponto de vista de Pery (2015) a carência de mão-de-obra, está posta, continuará sendo um gargalo durante um bom tempo, razão pela qual mais do que necessário, o fortalecimento da Atenção Primária ou atenção Básica, por que estudos indicam que ela e capaz de resolver grande parte dos problemas de saúde da população.

Contudo se a estratégia for bem executada, se houver um comprometimento da equipe, se houver realmente um planejamento, uma execução da política, um monitoramento controle e avaliação e correção dos rumos, porquanto o que existe no nosso pais no campo de Epidemiologia, Estados com uma cobertura muito grande de estratégia de saúde da família e lamentavelmente um número muito elevado de crianças com diagnóstico tardio já com algum nível de sequelas no caso de hanseníase.

Ao fazer uma leitura, percebe-se que não é o subfinanciamento, por que muito se ouve que dentre os problemas da saúde, o principal refere-se ao subfinanciamento, porém nas áreas que tem cobertura e os problemas persistem então se atribui ser falta de gerenciamento, falta os atributos da gestão como todo, desde governança, profissionalização, capacitação, eficiência, qualidade, e um olhar maior com relação ao cuidado da população adstrita, tanta na questão da saúde individual quanto coletiva. (Lima et al, 2019).

A promotora defende que de modo quando lança-se mão do monitoramento, controle e avaliação e demais de instrumentos de controle da execução das políticas públicas tomando-se por base, planos de saúde, metas pactuadas, ainda que fragilizados, percebe-se que não se executa e tudo fica desorganizado, na realidade precisa-se de um olhar muito acertado daquilo que não necessita de financiamento enquanto Ministério Publico zelar por esses serviços que são considerados conforme texto constitucional, as ações de serviço de saúde estão inseridos como os únicos considerados como de relevância pública.

Portanto cabe ao Ministério Público dentro de uma missão maior zelar pela execução de políticas públicas, tanto numa atuação que antecede a uma denúncia, no acompanhamento direto por meio do processo de acompanhamento de todos os instrumentos de planejamento, gestão e controle como de cada política seja de vigilância ou de assistência.

Certamente que enquanto órgãos de controle deve-se estar sempre fazendo auto critica na forma de atuar para dar resposta a população, as mesma exigidas do executivo. O Ministério Público tem um compromisso de dar visibilidade e 
aprimorar a forma de atuar na busca de eficiência da atuação institucional, inclusive isso que consta no Mapa Estratégico Nacional do Conselho Nacional do Ministério Público, portanto é meta institucional.

Quanto à atuação na dinâmica de redes existe uma necessidade de ter projetos claros e uniformizar os membros do Ministério público engajando-os no profundo conhecimento sobre o complexo sistema de saúde do Brasil, principalmente na questão sanitária.

Para Pery, as unidades hospitalares, no seu ponto de vista são os mais complexos, a primeira indagação a se fazer é porta de entrada, é a classificação de risco, percebe-se que não prática existe uma inversão da finalidade das unidades hospitalares acabam trazendo para si atendimento da atenção primaria e a atenção secundária. Quando questionados sobre os problemas da assistência, normalmente os gestores justificam que não conseguem ser mais eficientes por que acabam por arcar com uma responsabilidade que não é do hospital. Entretanto quando cobrados sobre a classificação de risco, para que possam estar executando aquelas ações cuja a unidade, ela é destinada não se enxerga um grande esforço desses gestores hospitalares em classificar risco.

No tocante o setor da Regulação deve ser empoderada, o gestor governamental deve exigir de todos os profissionais que demandem para o setor da Regulação, porque na prática sabe-se que no Brasil grande parte de hospitais, seja público ou prestadores, eles não se submetem ao sistema de Regulação.

Sabe-se que algumas pessoas ficam por décadas esperando um procedimento eletivo, no primeiro momento dar entender que esses sistemas são altamente ineficientes e na prática não é. Muito embora existam problemas com especialidades médicas, inclusive para cobrir escalas nos hospitais com sobrecarga de alguns com plantões extras, a falta de Regulação fere o princípio da Igualdade, sendo um dos princípios do SUS que deve ser respeitado. Aquela pessoa que não tem quem interfira por ela na prática quem é atendido, existem várias listas dentro dos hospitais e os próprios médicos tem sua agenda, o diretor que acaba interferindo, Unidade Hospitalar recebe pedidos de toda ordem ingerências de pedidos políticos, as liminares de ordem judicial, isso desorganiza essa fila e aquele usuário que não teve quem reclamar por ele, não chega a vez dele nunca. Então, a falta de Regulação é um dos principais problemas do nosso sistema de saúde.

Na análise da doutora Pery (2015), neste cenário complexo o desenho de atuação deste órgão de controle do sistema de saúde, no momento está evoluindo para definir prioridades de atuação do Ministério Público que estão inseridas no Art. 129, Inciso - 2 da CF/1988 que é zelar pelas ações e serviços de saúde, por meio de acompanhamento dos instrumentos de planejamento de gestão e do controle sistema único de saúde e da execução das políticas públicas de saúde.

Auditorias no âmbito do SUS têm publicações públicas estaduais e municipais disponíveis primorosas, ferramentas que são utilizadas a partir delas atuarem em intervir na gestão para que a gestão corrija as não conformidades. Grandes partes das não conformidades detectadas nos relatórios de auditória do SUS não se referem ao subfinanciamento, se referem ao processo de trabalho, a tomada de decisões do gestor ou das gerencias, maioria delas atributos de gestão que pode ser solucionada pela via administrativa.

\section{Conclusão}

O estudo realizado evidenciou que o prejuízo da população do não acesso aos serviços de alta complexidade do SUS é uma realidade em muitas unidades de saúde, e que referem-se a ineficiente gestão de recursos humanos pelo não cumprimento de carga horaria de alguns médicos que acarreta para a população adstrita ficar desassistida, e o problema de saúde que poderia ser enfrentado no primeiro nível de Atenção Básica ou Primaria, se perde a oportunidade e em muitos casos, a situação de saúde se agrava requerendo uma assistência no segundo nível de Atenção ou até mesmo no Terceiro, tornando-se um prejuízo para a população tanto do ponto de vista individual, coletivo quanto para o sistema que onera o erário. 
Contudo, um direito social humano básico e inacessível, a saúde requer um posicionamento de nível nacional, intervindo na sociedade por meio de políticas públicas e da prestação de serviços públicos, para garantir a dignidade de todas as pessoas sem distinção ou preconceitos, de ter saúde adequada, nos aspectos físicos, psicológicos e sociais, e tratar a saúde como um bem individual, coletivo e em construção. É fato que os serviços públicos de saúde do Brasil estão em crise e requer intervenção do Estado para reduzir os problemas de saúde, as desigualdades sociais e realizar os mencionados direitos humanos básicos.

É impossível separar os vetores da dignidade humana e do direito à saúde, concretizando instrumento de efetividade e exigibilidade dos direitos fundamentais para o exercício da cidadania representada pela legitimação de direitos e pela perspectiva de afirmar princípios da solidariedade e da igualdade, já que o direito à saúde é direito à vida. Logo, os pressupostos do princípio da dignidade da pessoa humana, enquanto fator legitimador do direito à saúde, afirmam-se como um importante aliado da coletividade na busca pela concretização dos tão idealizados direitos fundamentais.

No ponto de vista dos Órgãos de controle de políticas pública de saúde a carência de mão-de-obra especializada, continuará sendo um gargalo já que a alta complexidade como conjunto de procedimentos que envolvem alta tecnologia e custo, tende a propiciar a população com acesso a serviços qualificados. Tais instituições defendem ser necessário, além do fortalecimento da Atenção Primária/Básica, por que ela e capaz de resolver grande parte dos problemas de saúde da população. Contudo se a estratégia for bem executada, se houver um comprometimento da equipe, ou realmente um planejamento, uma execução da política, um monitoramento controle e avaliação e correção dos rumos. Investir em capacitação desde os atributos da gestão como todo, governança, profissionalização, até um olhar maior com relação ao cuidado da população adstrita, tanta na questão da saúde individual quanto coletiva.

Certamente que grande parte das não conformidades detectadas nos relatórios de auditória do SUS não se referem ao subfinanciamento, mas se referem ao processo de trabalho, de tomada de decisões do gestor ou das gerencias, maioria delas atributos de gestão que pode ser solucionada pela via administrativa.

Entende-se que a temática possui poucos estudos, sendo assim, faz-se necessário primeiramente o aprimoramento de estudos sobre o prejuízo da população do não acesso aos serviços de alta complexidade do SUS, bem como o despertar do poder público para voltar o olhar e regulamentar em lei a definição desse problema social. Os aprofundamentos de estudo é fundamental para romper com o desrespeito de direito fundamental à saúde.

Em suma, pode-se afirmar que os objetivos propostos inicialmente no estudo foram alcançados, mesmo havendo escassez de estudos publicados sobre a temática, foi possível discorrer sobre os fatores que influenciam o não acesso da população aos serviços de alta complexidade do SUS, bem como compreender como funciona a atenção à saúde.

\section{Referências}

Baptista, A. (2011). Os desafios enfrentados para manter os serviços da alta complexidade. Revista Brasileira de Saúde, 4(4), 1-22. http://www.osdesafiosenfrentadospelasaude.com.br

Bardin, P. (2004). Execução dos repasses do SUS. Revista Brasileira de Enfermagem, 12(4), 10-80. http://www.execussaodosrepasssesdosus.com.br

Bittar, O. J. N., Biczyk, M., Serinolli, M. I., Novarett, M. C. Z., \& Moura, M. M. N. de. (2018). RELATO DE CASO. Sistemas de informação em saúde e sua complexidade. Rev. Adm. Saúde. 18(70). http://dx.doi.org/10.23973/ras.70.77.

Brasil. (1988). Constituição da República Federativa do Brasil de 1988. http://www.planalto.gov.br/ccivil_03/constituicao/constituicao.htm.

Cayres, G. R. M., Marques, G. M., \& Leão Jr, T. M. de A. (2020). Afronta ao Princípio da Dignidade da Pessoa Humana frente ao colapso dos direitos basilares da Constituição Federal de 1988: Educação, Saúde e Segurança Pública. 2020.

Chagas, V. O., Provin, M. P., \& Amaral, R. G. (2016). Demandas judiciais para o acesso ás ações e aos serviços de saúde: Uma revisão integrativa. Revista Varia Scientia - Ciências da Saúde, 2(1).

Conselho Nacional de Secretários de Saúde - CONASS. (2015) Sistema Único de Saúde. Assistência de média e alta complexidade. Coleção para entender a gestão do SUS. (4). www.conass.org.br/biblioteca 
Fernandes, V. C., \& Sousa, C. L. de. (2020). Aspectos históricos da saúde pública no Brasil: revisão integrativa da literatura. J Manag Prim Health Care. https://doi.org/10.14295/jmphc.v12.579

Gil, C. R. R., Luiz. I. C., \& Gil, M. C. R. (2016). Gestão pública em saúde: contexto de implantação e aspectos organizacionais da gestão do SUS. Universidade Federal do Maranhão. UNA-SUS/UFMA.

Lima, L. D. de., Albuquerque, M. V. de., Scatena, J. H. G., Melo, E. C. P. de., Oliveira, E. X. G. de., Carvalho, M. S., Pereira, A. M. M., Oliveira, R. A. D. de., Martinelli, N. L., \& Oliveira, C. F. de. (2019). Arranjos regionais de governança do Sistema Único de Saúde: diversidade de prestadores e desigualdade espacial na provisão de serviços. Cadernos de Saúde Pública, 35(2). https://www.scielo.br.

Machado, C. V., Baptista, T. W. F., \& Lima, L. D. (2018). Políticas de Saúde Pública: continuidade e mudanças. Editora Fiocruz. https://portal.fiocruz.br

Martini, S. R., \& Sturza, J.M. (2017). A dignidade humana enquanto princípio de proteção e garantia dos direitos fundamentais sociais: o direito à saúde. Cadernos Ibero-Americanos de Direito Sanitário, 6(2), 25- 41, 2017. https://doi.org/10.17566/ciads.v6i2.367

Mendes, E. V. (2019). O Dilema do SUS. https://www.conass.org.br/biblioteca/desafios-do-sus

Nahsan, G., Martins, J. N., Daltro. O. F., \& Bianchi, E. (2020). O direito social fundamental á saúde. Revista Faipe; 10(2):88-94, https://www.revistafaipe.com.br/index.php/RFAIPE/article/view/247

Pery, M. R. de A. (2015). Política e Gestão da Saúde Pública para o Ministério Público, Atenção à Saúde no SUS (Atenção básica, média e alta complexidade). Tocantins. https://www.arca.fiocruz.br/handle/icict/16763

Queiroz, R., \& Sarmento. C. (2021). Média e Alta Complexidade do SUS. Saúde Coletiva-Universidade Estadual de Feira de Santana/BA, 2021. https://www.youtube.com/watc?v=C8ePDVepCng

Ramos, P. L. C. (2018). Referência e contra referência no SUS: revisão integrativa da literatura. Trabalho de Conclusão de Curso (Bacharelado em Saúde Coletiva) - Universidade de Brasília - UnB. Brasília, 2018.

Ramos, R. S, Gomes A. M. T, Oliveira D. C, Marques S. C, Spindola T, \& Nogueira, V. P. F. (2016). O acesso às ações e serviços do Sistema Único de Saúde na perspectiva da judicialização. Revista Latino-Americana de Enfermagem. (2016). 24:e2797. https://www.scielo.br

Sarlet, I. W. (2015). Dignidade da pessoa humana e Direitos Fundamentais CF 1988. Livraria do Advogado.

Thomaz, M. C. A. (2018). Urgência e Emergência em Enfermagem. Editora e Distribuidora Educacional S.A, 2018. 